\title{
Update and Supplementary Articles Proteins of SARS CoV-2, Which Causes COVID-19, and the Interacting Proteins
}

\author{
Francis K. Yoshimoto ${ }^{1}$ (D) $\cdot$ Lawrence J. Berliner $^{2}$ \\ Accepted: 13 May 2021 / Published online: 21 May 2021 \\ (c) The Author(s), under exclusive licence to Springer Science+Business Media, LLC, part of Springer Nature 2021
}

\begin{abstract}
Coronavirus disease 2019 (COVID-19), which is the pandemic caused by the virus, severe acute respiratory syndrome coronavirus-2 (SARS CoV-2), first appearing in December 2019, continues to confound the world. In this update we provide insights into how some of the new mutant variant strains of SARS CoV-2 have evolved to be more infective. We also introduce our supplement of the special issue on the topic of the proteins of SARS CoV-2 in the Protein Journal, which follows this introduction.
\end{abstract}

Keywords SARS CoV-2 $\cdot$ Proteins $\cdot$ Spike protein $\cdot$ ACE2 protein $\cdot$ Mutants $\cdot$ Enzymes

COVID-19 (coronavirus disease-2019), the pandemic caused by the virus, SARS CoV-2, has become an ongoing problem of the global community since December 2019. Now that vaccinations are helping mitigate the effects of COVID-19, there seems to be some relief. However, this global pandemic is an evolving situation and current global research efforts are focused on how to slow down the rapid spread of the more infective SARS CoV-2 mutants (see Tables 1 and 2 for select examples) [1]. One potentially confusing part of these mutant strains [2] are the various nomenclature systems employed to refer to the different strains [3]. Of particular interest of the mutant strains are the variants that have mutations in the spike protein of the virus (Fig. 1). The spike protein is a trimer. Figure $1 \mathrm{~A}$ shows the spike protein in its closed conformation where each protomer is colored differently (blue, green, and red). In Fig. 1B, the spike protein is bound to the human ACE2 protein (cyan). All structures in the Figs. 1, 2, 3 and 4 were generated using Chimera software [4].

In order to navigate the location of the mutations on the spike protein of each strain shown in Tables 1 and 2, Fig. 2 shows the spike protein (PDB: 6VXX, the structure itself

Francis K. Yoshimoto

francis.yoshimoto@utsa.edu

1 University of Texas at San Antonio (UTSA), San Antonio, TX, USA

2 University of Denver, Denver, CO, USA has residues 28-1147) colored by four different regions (the spike protein is 1273 amino acids in length-position 1-300 is red, 301-600 is yellow, 601-900 is green, and 901-1200 is blue). For clarity, Fig. 3 shows the structures of these individual ranges of the spike protein. The mutations are labeled in the sequences shown in Fig. 2B and C.

These mutant strains arise from the misincorporation of complementary nucleotides during replication [5] by the low-fidelity [6] RNA-dependent RNA polymerase complex. Furthermore, these mutant strains are likely to be more infective because they have a higher affinity towards the human receptor protein (ACE2). In particular, the spike protein of the UK variant strain (Table 1, Entry 1, also known as VOC202012/01 - “variant of concern" 202012/01) had a tenfold greater affinity towards the ACE2 protein compared to the original strain [7]. One explanation of the enhanced affinity towards the ACE2 protein in these mutations could be due to an introduction of a potential salt bridge when a charge is incorporated. For instance, mutants B1.427 and B1.429 have a leucine mutated to an arginine at position 452 (L452R) (Table 2, entries 4 and 5). Careful inspection of the structure of the SARS CoV-2 spike protein complexed with the human ACE2 protein shows that a glutamate on the ACE2 protein (E35) is near the residue-L452 on the spike protein (9.1 $)$ ) (Fig. 4). A mutation at position 452 to an arginine on the spike protein will potentially introduce a salt bridge between the spike and ACE2 proteins (i.e. positively charged R452 will interact with the negatively charged residue, E35). Other factors that potentially enhance the 
Table 1 Mutant strains of SARS CoV-2 that are more infective than the original strain

\begin{tabular}{|c|c|c|c|c|c|c|}
\hline \multirow[t]{2}{*}{ Entry } & \multirow{2}{*}{$\begin{array}{l}\text { Name of strain: Nextstrain } \\
\text { [8], Pango lineage [9] }\end{array}$} & \multicolumn{4}{|c|}{ Mutation on the spike protein ${ }^{\mathrm{a}}$} & \multirow[t]{2}{*}{ Original geographical location } \\
\hline & & $\{0-300\}$ & $\{301-600\}$ & $\{601-900\}$ & $\{901-1200\}$ & \\
\hline 1 & 20I/501Y.V1, B.1.1.7 & $\begin{array}{l}\Delta 69 / 70 \\
\Delta 144\end{array}$ & $\begin{array}{l}(\mathrm{E} 484 \mathrm{~K}), \\
(\mathrm{S} 494 \mathrm{P}), \\
\mathrm{N} 501 \mathrm{Y}, \\
\text { A570D }\end{array}$ & $\begin{array}{l}\text { D614G, } \\
\text { P681H } \\
\text { T761I }\end{array}$ & $\begin{array}{l}\text { S982A, } \\
\text { D1118H } \\
(\mathrm{K} 1191 \mathrm{~N})\end{array}$ & United Kingdom (U.K.) \\
\hline 2 & 20H/501Y.V2, B.1.351 & $\begin{array}{l}\text { D80A, } \\
\text { D215G, } \\
\Delta 241 / 242 / 243\end{array}$ & $\begin{array}{l}\mathrm{K} 417 \mathrm{~N}, \\
\mathrm{E} 484 \mathrm{~K}, \\
\mathrm{~N} 501 \mathrm{Y}\end{array}$ & $\begin{array}{l}\text { D614G, } \\
\text { A701V }\end{array}$ & & South Africa \\
\hline 3 & 20J/501Y.V3, P.1 & $\begin{array}{l}\text { L18F, } \\
\text { T20N, } \\
\text { P26S, } \\
\text { D138Y, } \\
\text { R190S }\end{array}$ & $\begin{array}{l}\text { K417T, } \\
\text { E484K, } \\
\text { N501Y }\end{array}$ & $\begin{array}{l}\text { D614G, } \\
\text { H655Y }\end{array}$ & T1027I & Brazil (subsequently Japan) \\
\hline
\end{tabular}

${ }^{a}$ Mutations shown in parentheses mean some sequences had them but not all

Table 2 Mutant strains of SARS CoV-2 that are more infective than the original strain (continuation from Table 1)

\begin{tabular}{|c|c|c|c|c|c|c|}
\hline \multirow[t]{2}{*}{ Entry } & \multirow{2}{*}{$\begin{array}{l}\text { Name of strain: Nextstrain } \\
\text { [8], Pango lineage [9] }\end{array}$} & \multicolumn{4}{|c|}{ Mutation on the spike protein } & \multirow[t]{2}{*}{ Original geographical location } \\
\hline & & $\{0-300\}$ & $\{301-600\}$ & $\{601-900\}$ & $\{901-1200\}$ & \\
\hline 4 & 20C/S:452R, B1.427 & & $\mathrm{L} 452 \mathrm{R}$ & D614G & & California (U.S.A.) \\
\hline 5 & 20C/S:452R, B1.429 & $\begin{array}{l}\text { S13I, } \\
\text { W152C }\end{array}$ & $\mathrm{L} 452 \mathrm{R}$ & D614G & & California (U.S.A.) \\
\hline
\end{tabular}

\section{(A) Spike protein (closed conformation)}

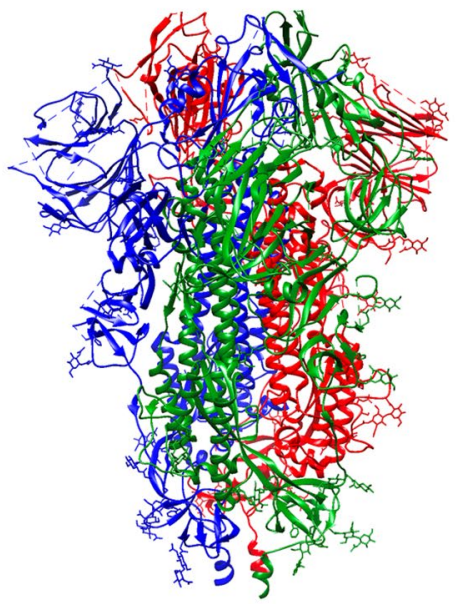

Fig. 1 A SARS CoV-2 spike protein (PDB ID: 6VXX). B SARS CoV-2 spike protein bound to the human ACE2-receptor protein (PDB ID: 7A96). The green protomer has its receptor binding domain (RBD) pointing up and is bound to the ACE2 protein (cyan). The
(B) Spike protein-ACE2 protein complex

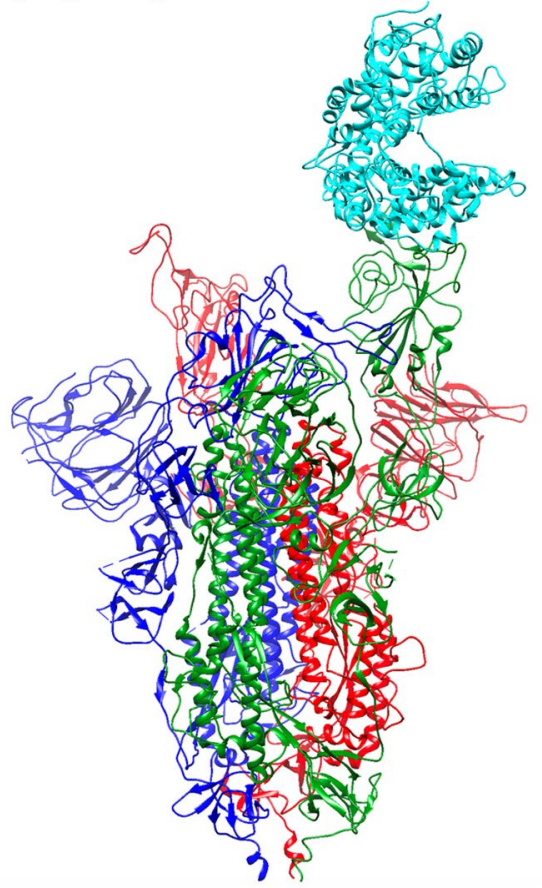

red protomer has its RBD pointing up in position to bind to a second ACE2 protein. The blue protomer has its RBD pointing in the closed conformation (Color figure online) 
(A)

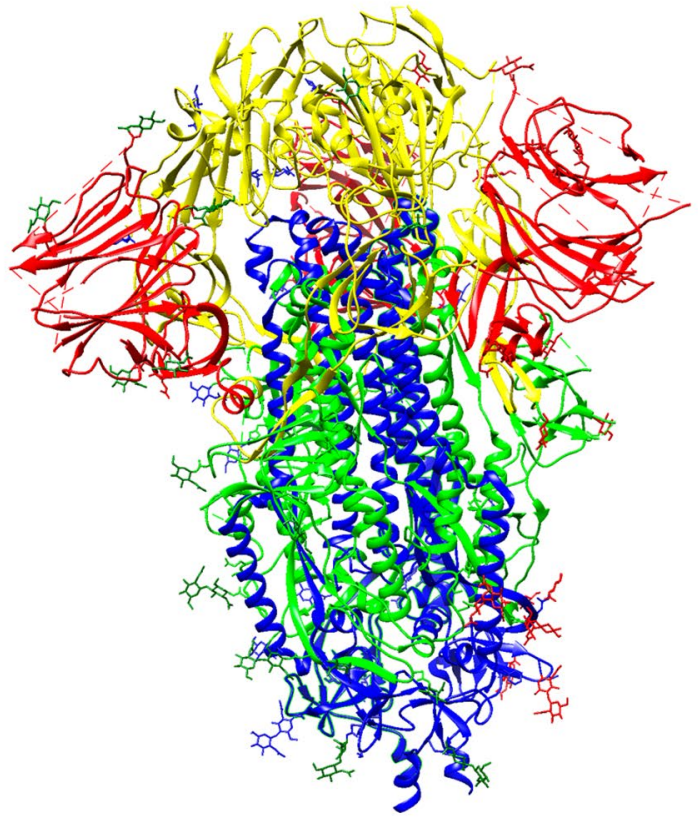

(B) Residues 1-300 (red), 301-600 (yellow)

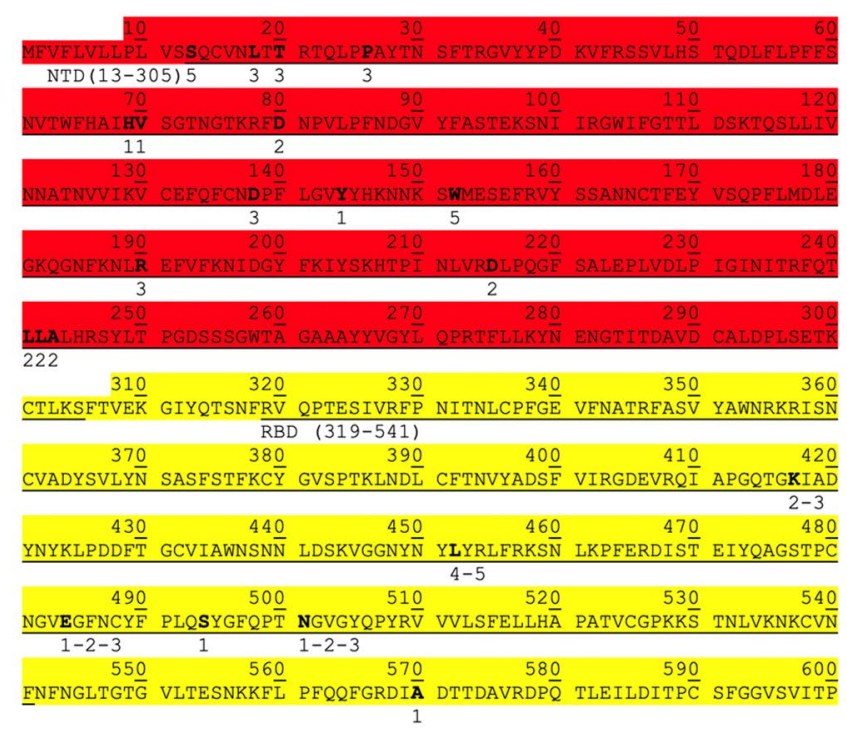

Fig. 2 A Spike protein (closed conformation, PDB: 6VXX) colored where position 1-300 is red, position 301-600 is yellow, position 601-900 is green, and position $901-1200$ is blue. B Sequence of the spike protein from 100 to 600 (colored as described in (A) of this figure). C Sequence of the spike protein from 601 to 1200 (colored as described in (A) of this figure). The numbers below the bold residues in the sequences refer to the changes in residues for each

interaction between the spike and ACE2 proteins are discussed in the review article in this special issue.

Another aspect that may be important to consider regarding these mutant variants is that some monoclonal antibodies
(C) Residues 601-900 (green), 901-1200 (blue)

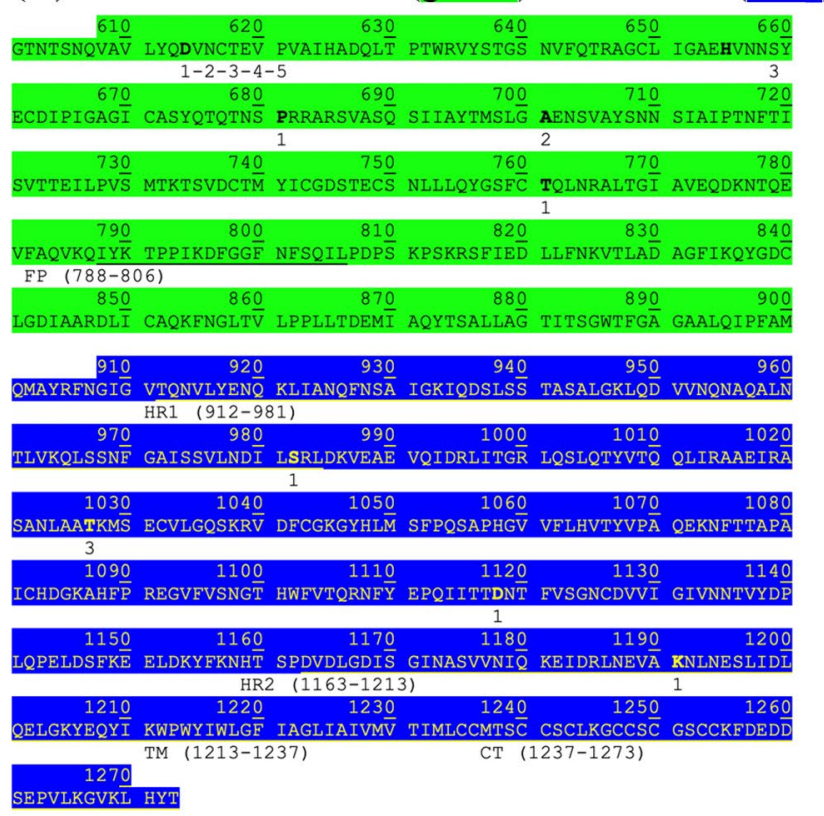

mutant strain presented in Tables 1 and 2. For mutant strains that have the same mutations, the numbers of the entries are separated by a hyphen-for example, the N501Y mutation is in entries 1, 2, and 3 from Table 1; therefore, position 501 is labeled with "1-2-3". $N T D \mathrm{~N}$-terminal domain, $R B D$ receptor binding domain, $H R 1$ heptad repeat sequence 1, HR2 heptad repeat sequence 2, TM transmembrane domain, $C T$ cytoplasm domain (Color figure online)

and vaccines may not be as effective towards treating and preventing COVID-19. A selection of current mutant strains that are circulating in the world are listed in Tables 1 and 2. 
(A) Residues 0-300 (red)

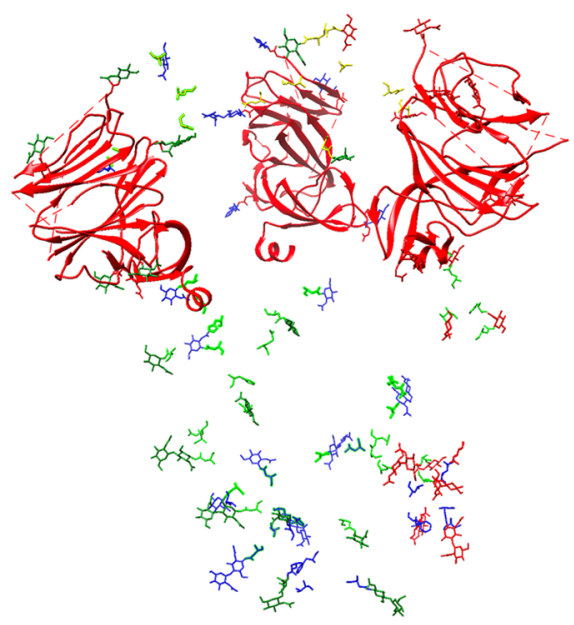

(C) Residues 601-900 (green)

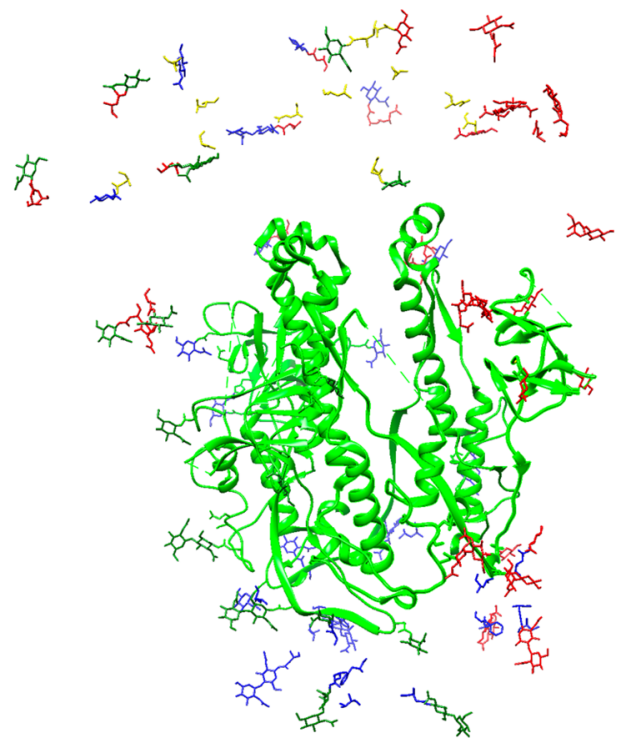

(B) Residues 301-600 (yellow)

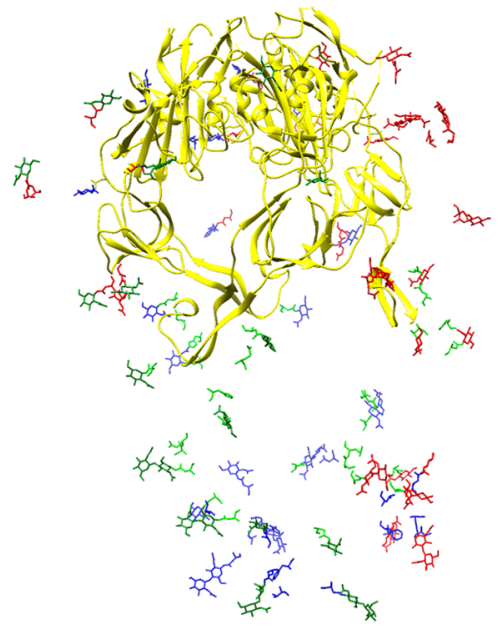

(D) Residues 901-1200 (blue)

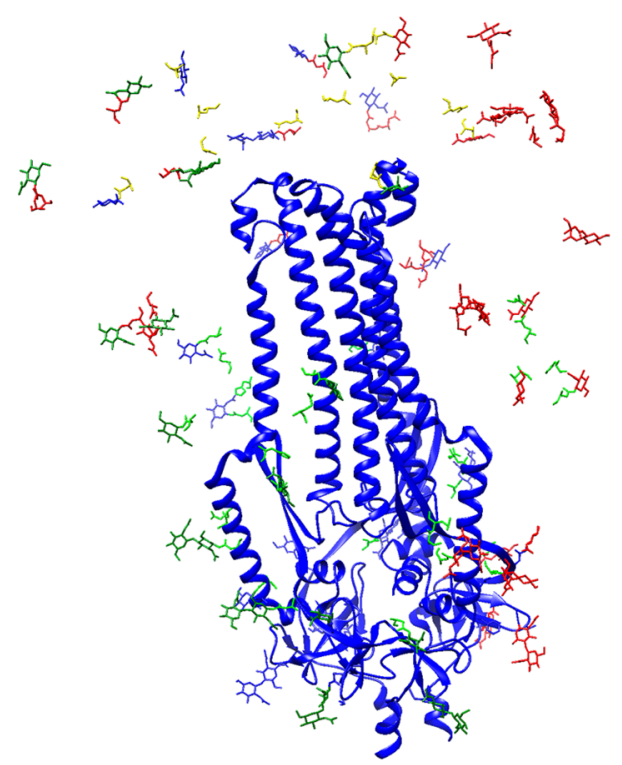

Fig. 3 The spike protein with residues colored in the four different ranges: A 0-300 (red), B 301-600 (yellow), C 601-900 (green), and D 901-1200 (blue). Glycan moieties shown for reference (Color figure online)

Herein, we disclose our own update and efforts in the Protein Journal on recent publications focused on helping us understand SARS CoV-2 to help the worldwide research community. We have combined these manuscripts into the second part of our special issue on COVID proteins.

Recently, in Cell Biochemistry and Biophysics (Volume 79 - Number 2 - pp. 175-188, June 2021) in a manuscript entitled, "Piece of the puzzle: Remdesivir disassembles the multimeric SARS-CoV-2 RNA-dependent RNA polymerase complex," Soliman and co-workers have reported on some molecular dynamics simulations on how remdesivir triphosphate binds to the RNA-dependent RNA polymerase
(NSP12-NSP7-NSP8) complex of SARS CoV-2. [https:// link.springer.com/article/10.1007/s12013-021-00977-y].

In this special issue supplement on the topic of COVID proteins, we feature four articles:

(1) A review on the biochemical activities of the nonstructural proteins (NSPs) and the spike protein and a description of a recent ribosomal profiling study that revealed 23 new SARS CoV-2 proteins

(2) An in silico study of the mutational stability of SARS CoV-2 proteins 
Fig. 4 A Spike protein from SARS CoV-2 (tri-colored: red, blue, green) bound to human ACE2 protein (cyan) - PDB ID: $7 \mathrm{KNE}$. Boxed is residue L452 on the spike protein and residue E35 on the ACE2 protein. B The zoomed in picture of L452 (spike) and E35 (ACE2) (Color figure online)
(A)

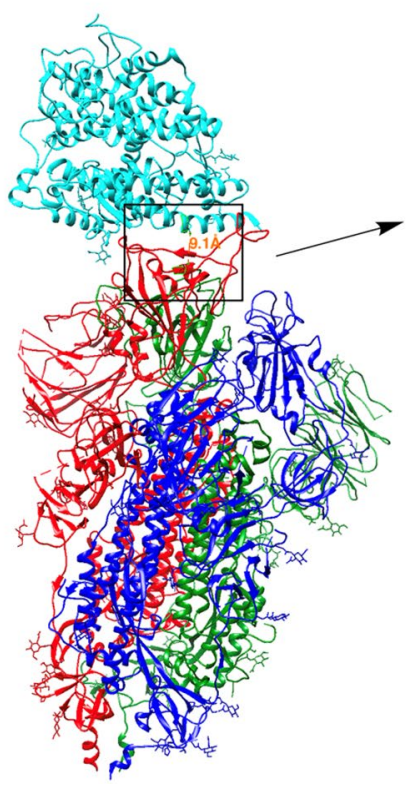

(B)

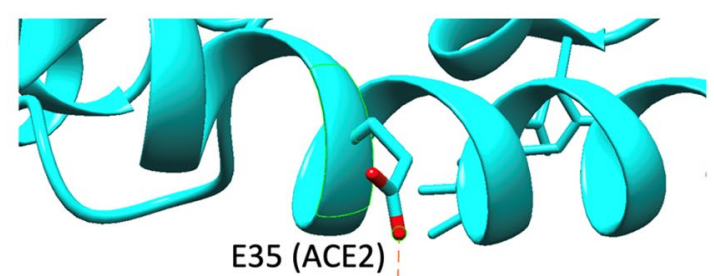

E35 (ACE2)

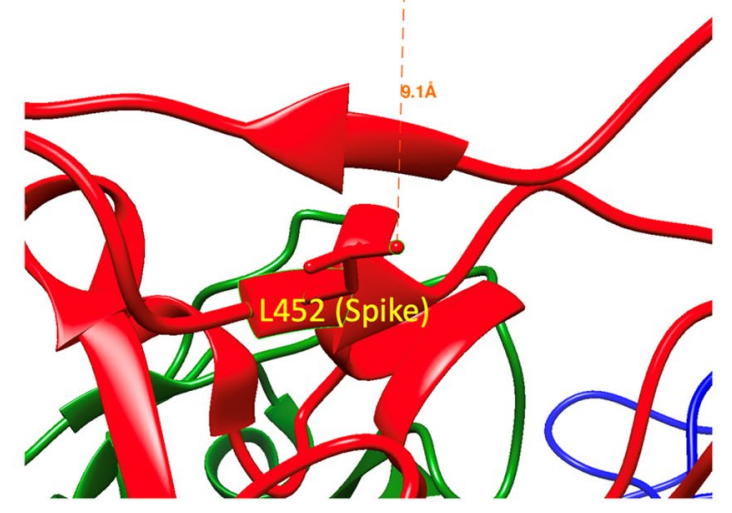

(3) A docking study of milk peptides binding to various SARS CoV-2 proteins

(4) A docking study of possible anti-SARS CoV-2 main protease inhibitors

We hope that these articles in this special issue will continue to help advance our knowledge in combating SARS CoV-2, the virus that caused COVID-19.

\section{References}

1. https://www.cdc.gov/coronavirus/2019-ncov/science/sciencebriefs/scientific-brief-emerging-variants.html. Accessed 18 May 2021

2. Wang R, Chen J, Gao K, Hozumi Y, Yin C, Wei G-W (2021) Analysis of SARS-CoV-2 mutations in the United States suggests presence of four substrains and novel variants. Commun Biol 4:228

3. Rambaut A, Holmes EC, O’Toole A, Hill V, McCrone JT, Ruis C, du Plessis L, Pybus OG (2020) A dynamic nomenclature proposal

for SARS-CoV-2 lineages to assist genomic epidemiology. Nat Microbiol 5:1403

4. Pettersen EF, Goddard TD, Huang CC, Couch GS, Greenblatt DM, Meng EC, Ferrin TE (2004) UCSF Chimera-a visualization system for exploratory research and analysis. J Comput Chem 25:1605

5. Campagnola G, McDonald S, Beaucourt S, Vignuzzi M, Peersen OB (2015) Structure-function relationships underlying the replication fidelity of viral RNA-dependent RNA Polymerases. J Virol 89:275

6. Peck KM, Lauring AS (2018) Complexities of viral mutation rates. J Virol 92:e01031

7. Liu H, Zhang Q, Wei P, Chen Z, Aviszus K, Yang J, Downing W, Jiang C, Liang B, Reynoso L et al (2021) The basis of a more contagious 501Y.V1 variant of SARS-CoV-2. Cell Res. https:// doi.org/10.1038/s41422-021-00496-8

8. https://nextstrain.org/

9. https://cov-lineages.org/

Publisher's Note Springer Nature remains neutral with regard to jurisdictional claims in published maps and institutional affiliations. 